\title{
Neutronics Analysis for ITER Cable Looms
}

\author{
Arkady Serikova ${ }^{\mathrm{a}}$, Luciano Bertalot ${ }^{\mathrm{b}}$, Ulrich Fischera ${ }^{\mathrm{a}}$, Matthew Clough ${ }^{\mathrm{c}}$, Alejandro Suarez ${ }^{\mathrm{b}}$
}

aKarlsruhe Institute of Technology KIT, Institute for Neutron Physics and Reactor Technology, Hermann-von-Helmholtz-Platz 1, 76344 Eggenstein-Leopoldshafen, Germany bITER Organization, Route de Vinon sur Verdon, 13115 Saint Paul Lez Durance, France

c National Nuclear Laboratory, Chadwick House, Birchwood Park, Risley, WA3 6AE, UK

\section{Introduction and Motivation: In-vessel and Divertor Cable Looms}

- Neutronics support for the design development of the ITER Diagnostics cabling system including its cable looms.

- The cable looms are distributed all around the ITER and attached to the inner wall of the Vacuum Vessel (VV) and under the divertor cassettes.

- The results include distributions of neutronics characteristics calculated with the MCNP5 3D Monte Carlo code assuming ITER operation with 0.54 Full Power Years on 500 MW fusion power of DT neutron source defined in the standard ITER B-lite neutronics model.

- The importance of precise calculation of nuclear heating distribution along the in-vessel cable looms is stressed in Ref. work [1]

\section{Loom's voxelization - for MCNP tallying}

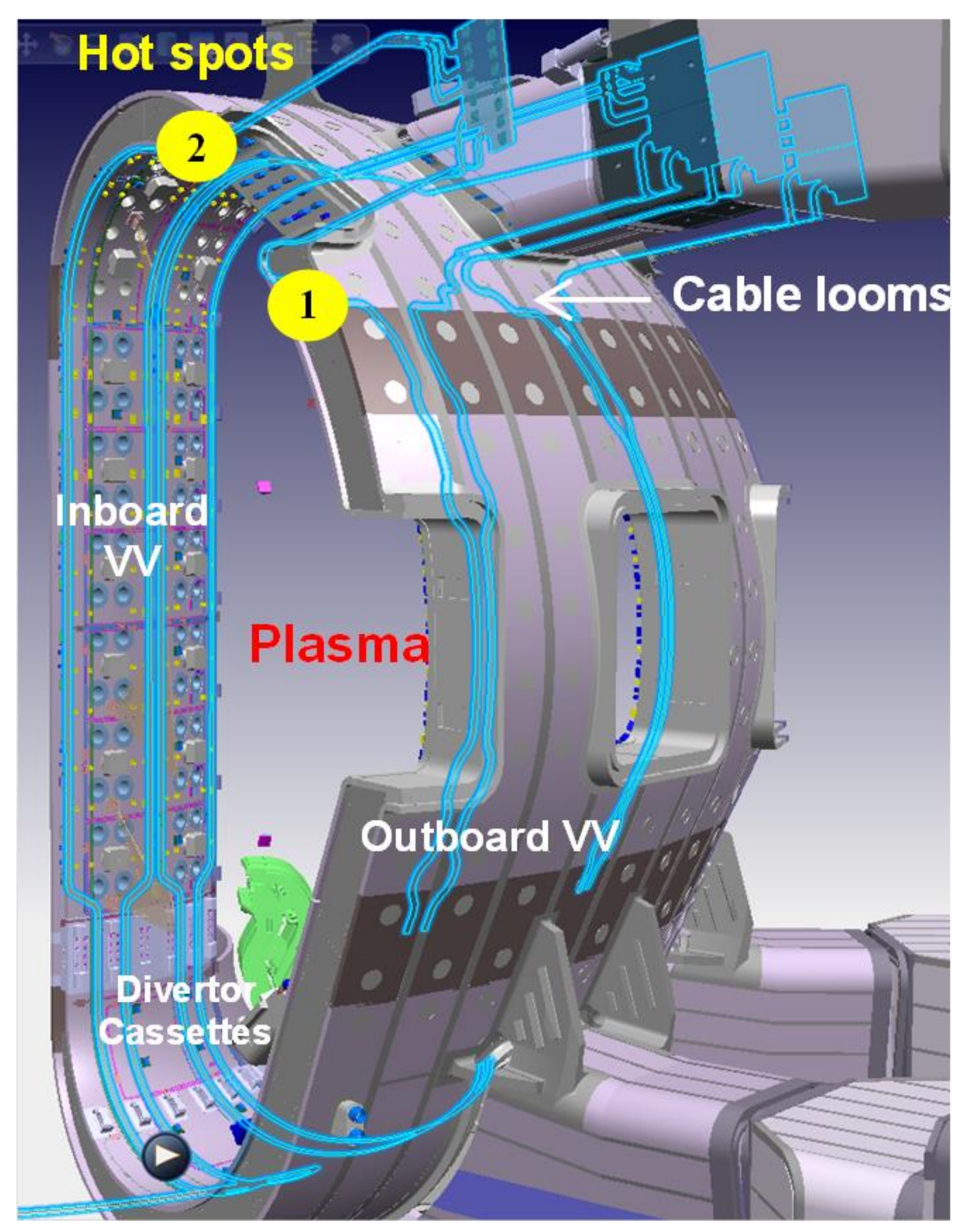

CAD model of ITER sector with highlighted counters of cable looms and two radiation hot spots.

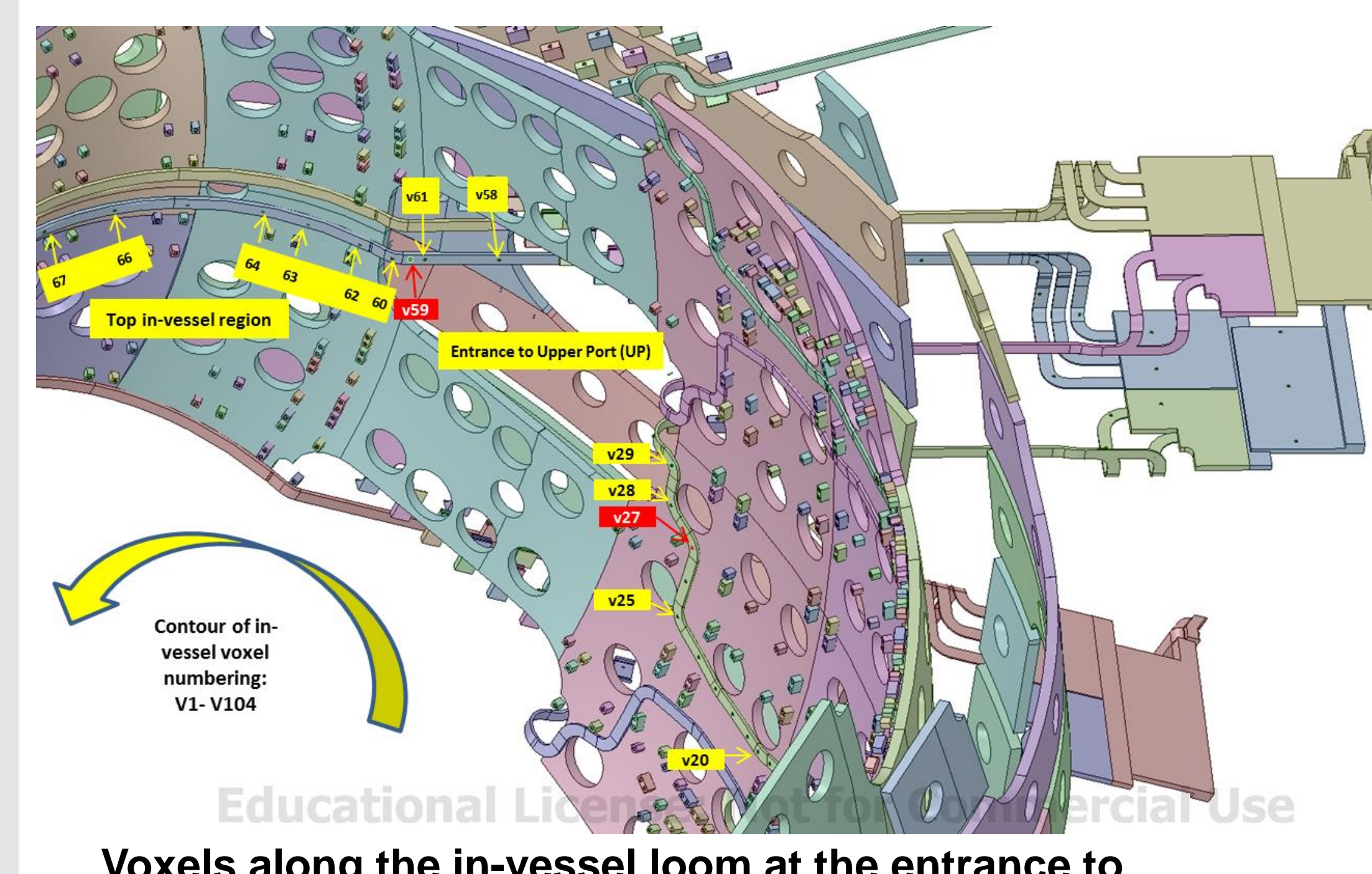

Upxels along the in-vessel loom at the entrance to
Uppert and Top of the in-vessel region

\section{Transmutation of Copper and Gold}

The major transmutation of gold and copper is observed on the $(n, g)$ radiative capture reactions. The maximum transmutation was observed in gold, amounted 3 atom\% for the highest radiation spot at the in-vessel loom, and 1 atom\% for the divertor cassette. Transmutation of copper is 100 times less than gold; it is 0.03 atom\% for the hot-spot at divertor an

${ }^{97} \mathrm{Au}(\mathrm{n}, \gamma){ }^{198} \mathrm{Au} \rightarrow{ }^{198} \mathrm{Hg}+\beta$

${ }^{65} \mathrm{Cu}(\mathrm{n}, \gamma)^{66} \mathrm{Cu}\left(\mathrm{T} 1 / 2=5\right.$ min beta decay)--> ${ }^{66} \mathrm{Zn}$

${ }^{63} \mathrm{Cu}(\mathrm{n}, \gamma){ }^{64} \mathrm{Cu}(\mathrm{T} 1 / 2=12.7 \mathrm{~h}$ positron decay $)-->{ }^{64} \mathrm{Ni}$

\begin{tabular}{|c|c|c|c|}
\hline $\begin{array}{l}\text { Voxel number at } \\
\text { peak }\end{array}$ & $\begin{array}{l}\text { Reaccition of } \\
\text { transmutation }\end{array}$ & $\begin{array}{c}{ }^{63} \mathrm{Cu} \\
\text { transmutation, } \\
\text { appmono.54 }\end{array}$ & 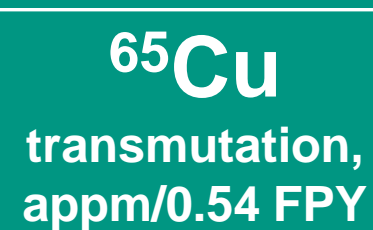 \\
\hline Wen & $\begin{array}{l}\text { total } \\
\text { total }\end{array}$ & $\begin{array}{l}8.10 E+00 \\
1.27 E+00\end{array}$ & $\begin{array}{l}9.28 \mathrm{E}-11 \\
2.29-01\end{array}$ \\
\hline & & 3.66 & $1.76 \mathrm{E}+02$ \\
\hline oxel \#17 on & total & $5.57 E+00$ & $6.12 E-01$ \\
\hline $\begin{array}{l}\text { mof divertior } \\
\text { side\#2 }\end{array}$ & & $\begin{array}{l}8.44 E-11 \\
2.67+02\end{array}$ & $\begin{array}{l}1.49 E-01 \\
1.28+02\end{array}$ \\
\hline & & & \\
\hline 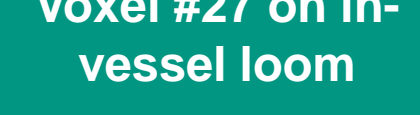 & tota & $2.38 E+00$ & $\begin{array}{l}4.38 E-01 \\
\end{array}$ \\
\hline & & & \\
\hline $\begin{array}{l}\begin{array}{l}\text { Voxele } f: 59 \text { on in- } \\
\text { vessel loom }\end{array}\end{array}$ & total (n,He) & $1.32 E+00$ & 2.45E-01 \\
\hline
\end{tabular}

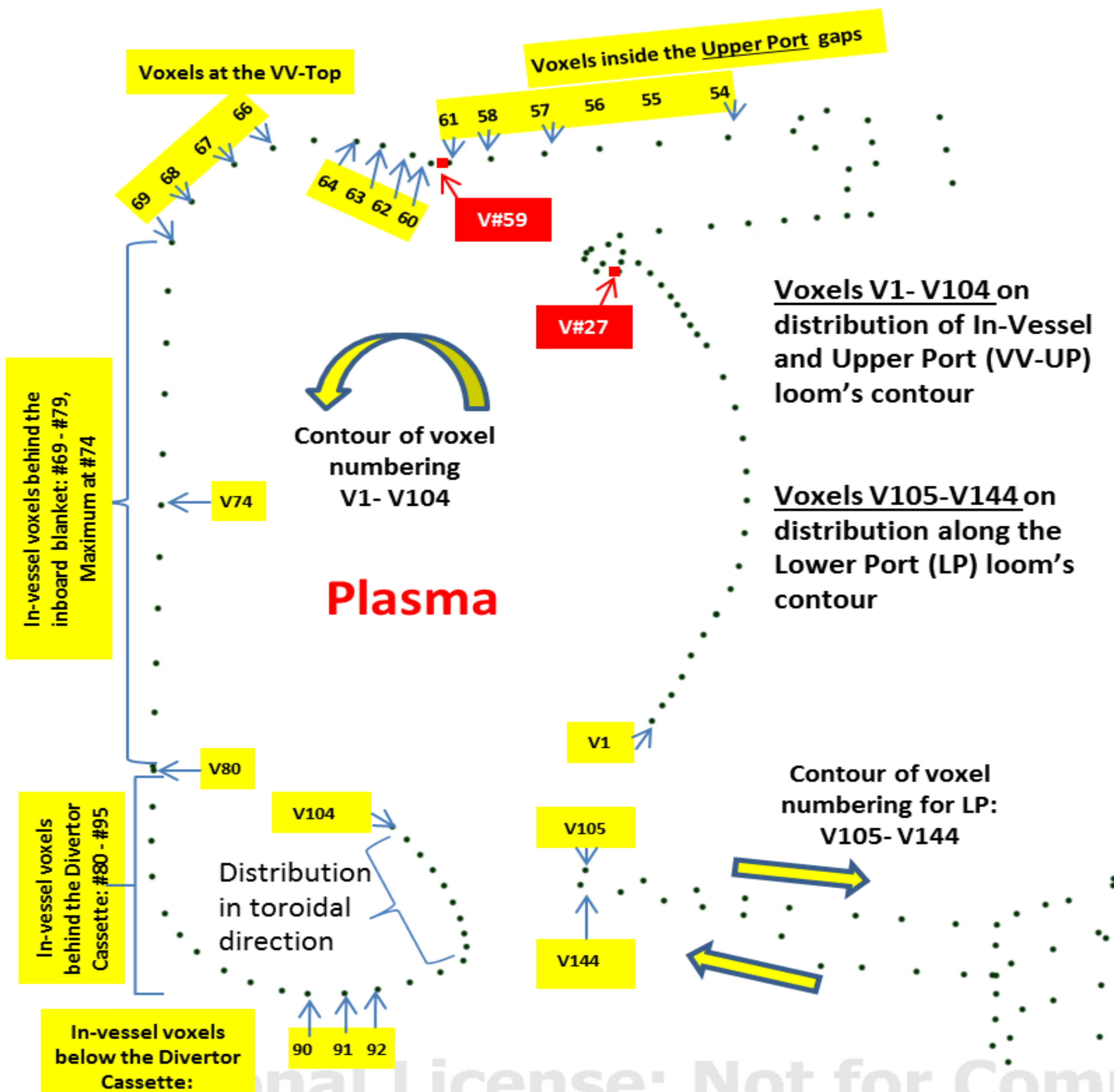

Distribution of the MCNP voxels in the poloidal direction along the in-vessel looms (outboard-VV, UP, top-VV,

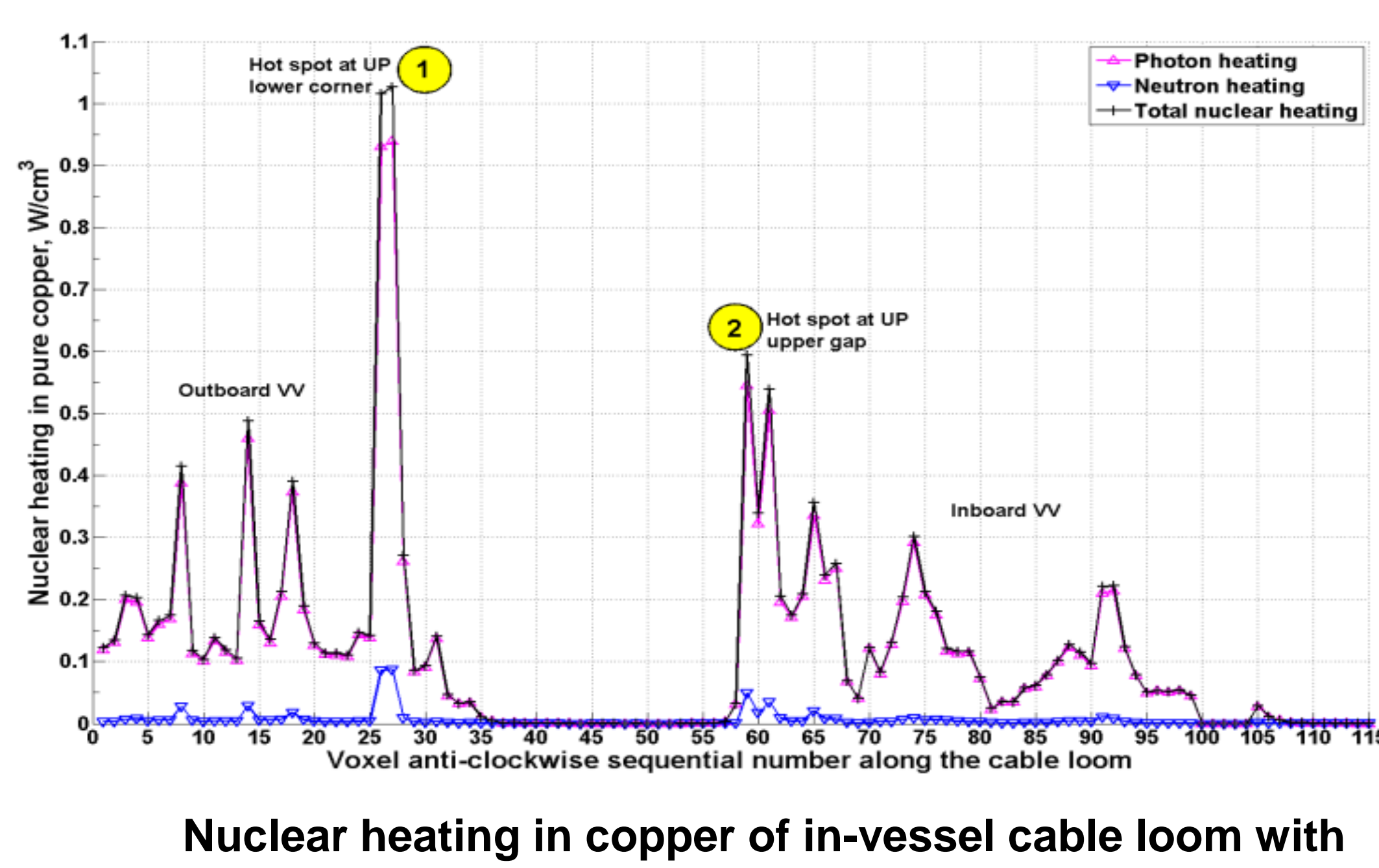
Nuclear heating in copper of in-vessel cable loom
labelling of two hot spots at Upper Port (UP).

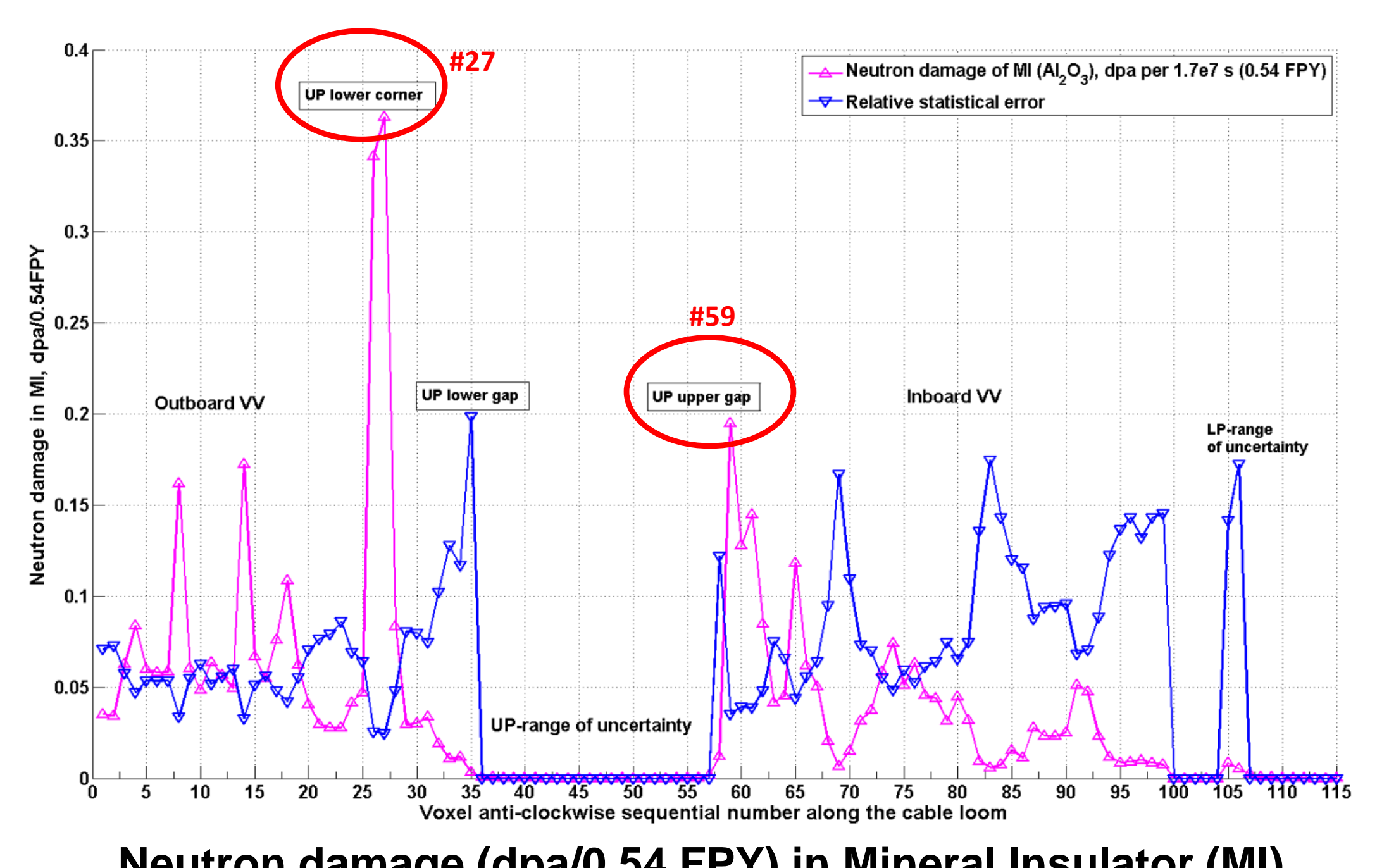

Neutron damage (dpa/0.54 FPY) in Mineral Insulator (MI) made of $\mathrm{Al}_{2} \mathrm{O}_{3}$ for the in-vessel cable loom.

\begin{tabular}{|c|c|c|c|}
\hline $\begin{array}{l}\text { Voxel number at peak } \\
\text { of radiation }\end{array}$ & $\begin{array}{l}\text { Reaction of } \\
\text { transmutation }\end{array}$ & $\begin{array}{c}\mathrm{Au} \\
\text { transmutation, } \\
\text { appm/0.54 FPY }\end{array}$ & $\begin{array}{l}\text { Relative stat. } \\
\text { error of Au } \\
\text { transmut. } \\
\text { reaction }\end{array}$ \\
\hline & to & 3.861 & \\
\hline livertor s & & 1.33E+04 & $\begin{array}{l}\text { 4.66E-02 } \\
8.98 E \mathrm{E}-02\end{array}$ \\
\hline Voxel \#17 on loom of & total $(n, p)$ & $2.49 \mathrm{E}-02$ & $\begin{array}{l}5.69 \mathrm{E}-02 \\
577 F-02\end{array}$ \\
\hline divertior side\#2 & (t) & $1.12 \mathrm{E}-\mathrm{C}$ & $\begin{array}{l}\text { b./.3E-02 } \\
1.35 \mathrm{E}-0\end{array}$ \\
\hline $\begin{array}{l}\text { Voxel \#27 on in-vessel } \\
\text { loom }\end{array}$ & $\begin{array}{l}\text { total }(n, p) \\
\text { total }(n, \mathrm{H})\end{array}$ & $\begin{array}{l}1.10 E-02 \\
.0 E\end{array}$ & $\begin{array}{l}2.99 \mathrm{E}-02 \\
3.04 \mathrm{E}-02\end{array}$ \\
\hline issel & $\begin{array}{c}(\mathbf{n , g}) \\
\text { total }(\mathbf{n , p}) \\
\text { total }(\mathbf{n}, \mathrm{He})\end{array}$ & $\begin{array}{l}2.97+4044 \\
4.16 \mathrm{E}-02 \\
6.19 \mathrm{E}-03\end{array}$ & $\begin{array}{l}4.15 E-02 \\
4.21 E-02\end{array}$ \\
\hline
\end{tabular}

\section{Distributions for the looms at divertor cassette}

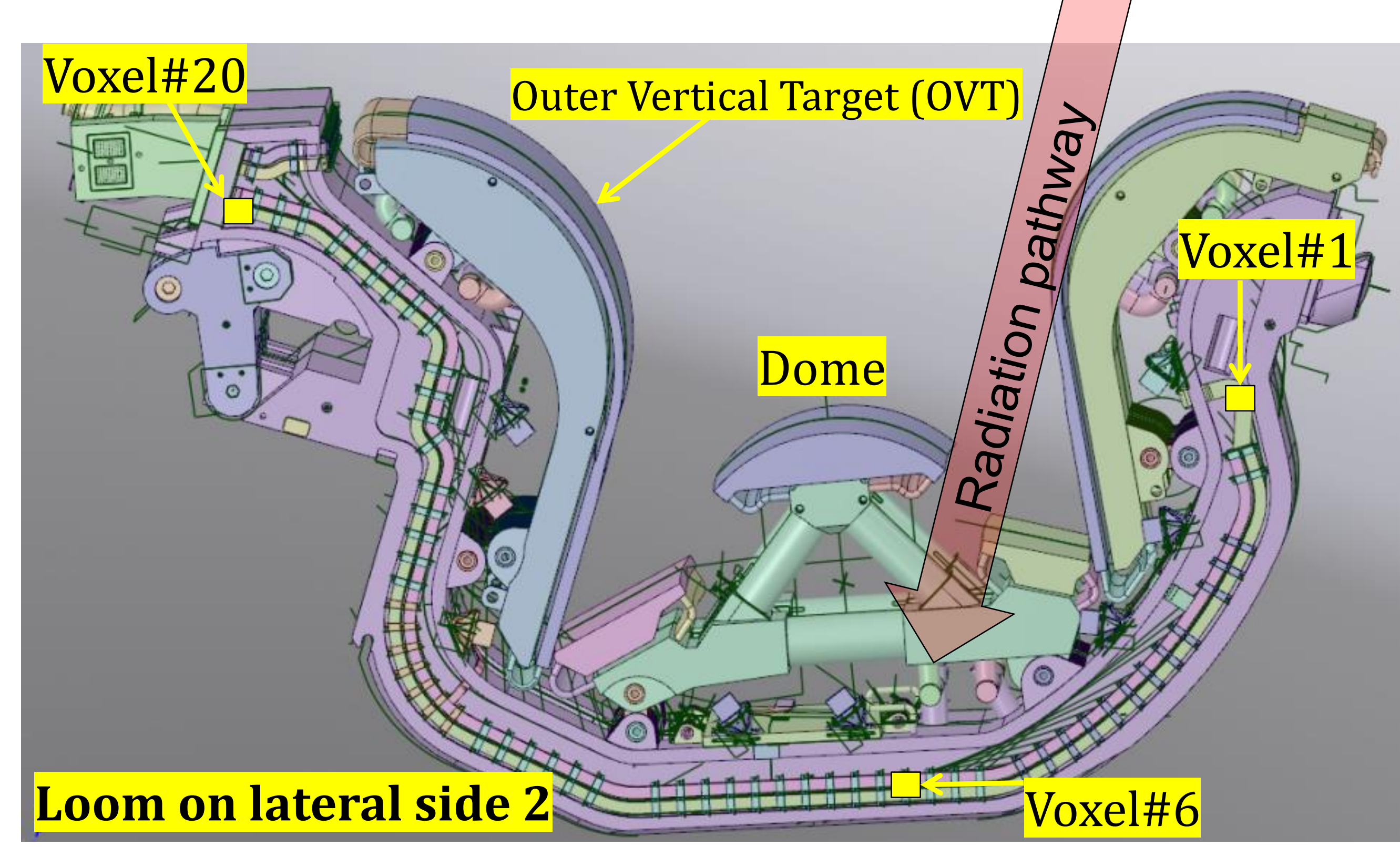

Vertical cut of the CAD model of the divertor cassette with the cable loom on the lateral side \#2.
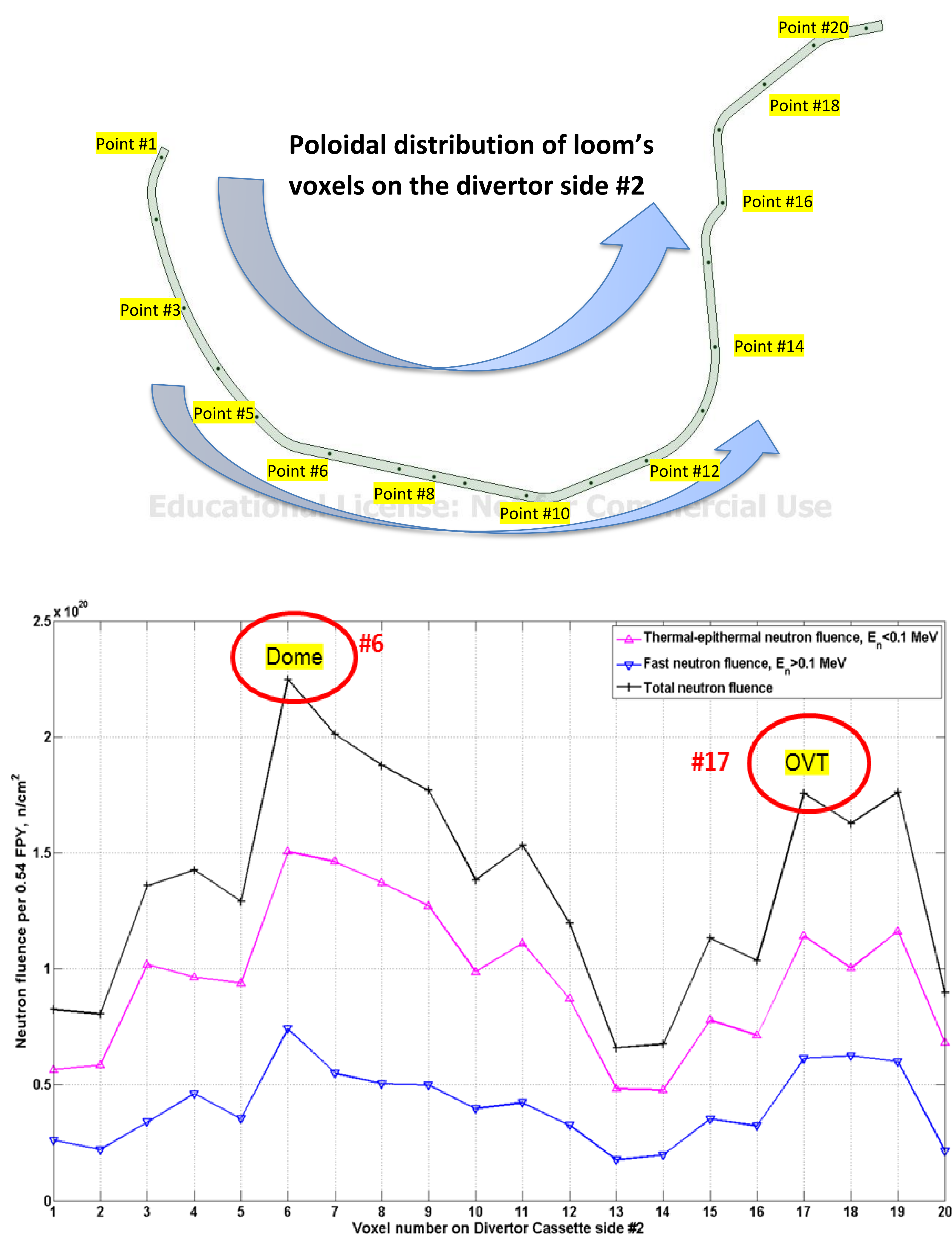

Neutron fluence distributions for the loom along the divertor cassette lateral side \#2.

\section{Conclusions and Further Analyses}

The peak value for nuclear heating is $\sim 1 \mathrm{~W} / \mathrm{cc}$ in Inconel alloy 718 . It is important is to reduce the temperature variation along the cable looms by achieving good thermal contact with the water cooled VV structure.

Based on the nuclear heating results, the temperature distributions will be estimated later. The temperature gradients together with the nuclear

transmutation of the cable's copper could result in formation of thermocouples and hence non-inductive parasitic voltages due the Radiation-Induced Thermoelectric Sensitivity (RITES) effect [2].

\section{Acknowledgment}

This work has been funded by the ITER Organization under the ITER contract $\mathrm{Nr}$. 1O/4300000896 using an adaptation of the B-lite MCNP models. The views and opinions expressed herein do not necessarily reflect those of the ITER Organization. References

[1] J. González, M. Clough, A. Martin, N. Woods, A. Suarez, G. Martinez, Distribution of the in-vessel diagnostics, this SOFT Conference, Sep.29 $9^{\text {th }}$ Oct. $3^{\text {rd }} 2014$

[2] G. Vayakis, et al., Radiation-induced thermoelectric sensitivity (RITES) in ITER prototype magnetic sensors, Review of Scientific Instruments, 75 (2004) 4324-4327. 